wide experience was generously given to those working with him, and he endeared himself to them.

Humphrey received a number of awards from the engineering institutions, the Willans (1906), the Watt (1913), and the Telford (1897) Gold Medals, the Franklin Medal of the Franklin Institute and the Paris Premium of the Institution of Electrical Engineers (1930). He had three sons and two daughters; one son married a daughter, and one daughter married a son, of Prof. A. V. Hill. He was a member of all three engineering institutions, Civil, Mechanical and Electrical; a Fellow and Melchett Medallist (1939) of the Institute of Fuel, and an honorary fellow of the Imperial College. A. C. EGERTON

\section{Dr. D. F. Twiss}

By the death on May 23 of Dr. D. F. Twiss, the rubber industry has lost a distinguished pioneer scientific worker and a man universally esteemed by his colleagues in the industry. Born in Birmingham in 1883, Douglas Frank Twiss studied at Mason College and its successor, the University of Birming ham, where he graduated B.Sc. in 1902, afterwards carrying out research in organic chemistry under Prof. P. F. Frankland. During 1904-14 he was lecturer in chemistry at Birmingham Technical School (now Birmingham Central Technical College), and continued research work on organic sulphides and other sulphur compounds and selenides. Dr. Twiss became, indeed, a leading authority on the sulphur group of elements, and was joint author of vol. 7 (oxygen, sulphur, selenium, tellurium) of the wellknown "Text Book of Inorganic Chemistry" edited by J. Newton Friend. $\mathrm{He}$ was awarded research degrees by the Universities of Birmingham (D.Sc.), and London (B.Sc.).

This early interest in sulphur and its organic compounds was a fitting preparation for Dr. Twiss's real life-work, which lay in the field of rubber chemistry, including vulcanization by sulphur. The opportunity to enter this field came in 1914 when Dr. Twiss was engaged by the Dunlop Rubber Co., Ltd., as its first scientific worker. During his thirty. two years as chief chemist there grew up under his leadership a research team that has made outstanding contributions to rubber science and manufacturing techniques.

Dr. Twiss's earlier work on rubber was concerned with vulcanization by sulphur, the action of organic accelerators of vulcanization, and the important influence of zinc oxide and other metallic oxides on their activity. Of even greater importance to the development of the industry, however, has been the work pioneered by Dr. Twiss on the production of rubber articles directly from the liquid latex, without the usual intermediate stage of coagulating to produce dry rubber which then has to be worked ('masticated') on heavy machinery to render it fit for further processing. From the work of Twiss and his colleagues on latex has developed an entirely new and important branch of the rubber industry, producing vast quantities of cellular (foamed latex) rubber for upholstery, as well as rubber gloves, thread, and hosts of other articles, using methods which in essence are of elegant simplicity, though demanding a rigid physico-chemical control over that complex and sensitive material, rubber latex.

In the midst of these activities Dr. Twiss yet found time to be a willing helper and wise counsellor to many organizations connected with the rubber industry, notably the Institution of the Rubber Industry and the Research Association of British Rubber Manufacturers. There are many who will remember with gratitude and admiration the unfailing help which Dr. Twiss's intensely logical mind was able to give on innumerable problems. Through his work for these organizations, Dr. Twiss did much to foster both technical education and co-operative research in the rubber industry. In recognition of his outstanding services, the Institution of the Rubber Industry in 1934 conferred on Dr. Twiss the Colwyn Gold Medal.

For a man of such attainments and influence, Dr. Twiss was modest and retiring to a degree, but his sincerity of purpose and his conscientious and painstaking discharge of any duty that he undertookand these duties were many and varied-marked him out as a man above his fellows. His memory will always be an inspiration to those who had the privilege of knowing him. J. R. ScOTT

\section{Prof. E. L. Watkin}

THE death of Ernest Lucas Watkin, emeritus professor of mathematics in University College, Southampton, has severed one of the few remaining links with the difficult time when the College was struggling not only to deserve the name of University College, but even to keep in existence.

Prof. Watkin took his degree from St. John's College, Cambridge, being seventh wrangler in the Mathematical Tripos of 1898 , still remembered as 'Hudson's Year' for the galaxy of distinguished mathematicians who took the Tripos then. After a short time as lecturer in the University of Bristol, he was appointed in 1904 to the chair of mathematics at Southampton, which he held until 1930. Only those closely associated with him realized the burden of organization involved in a department in which many additional courses were necessary if the College were to survive, including heavy and increasing commitments to the technical side which is still part of the work of the College. He had great administrative ability, and though handicapped by persistent ill-health, carried out unfinchingly work which in these days would be shared by at least two people. His entire disregard of self brought him enthusiastic loyalty from his Department.

After retiring from the chair, he continued to act as deputy registrar and curator of the grounds of the College until increasing age and ill-health forced his permanent retirement.

Prof. Watkin's interests were unusually wide and all were useful to college life. He was an admirable gardener with a good knowledge of systematic botany which he was able to apply as curator of the grounds. He was president of the Chess Club, a strong supporter of all musical activities, an authority on the regulations of most varied and mixed bodies with examination and entrance requirements, and a repository of information on the past history of the College. He combined with all these a gift for friendship, a patient and understanding care for the difficulties of people who often proved tiresome and captious, and a loyalty to his chosen work which is past all praise.

A. M. Trout

WE regret to announce the death of Prof. W. E. Agar, C.B.E., F.R.S., emeritus professor of zoology in the University of Melbourne, on July 14, aged sixty-nine. 